\title{
Elektronik Devrelerdeki Silindirik Soğutuculardan Kaynaklanan Elektromanyetik Girişimlerinin 0-10 GHz Frekans Bandında Araştırılması
}

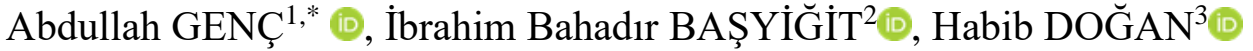 \\ 1,*'Isparta Uygulamalı Bilimler Üniversitesi, Teknoloji Fakültesi, Mekatronik Mühendisliği Bölümü, Isparta, \\ Türkiye \\ ${ }^{2}$ Isparta Uygulamalı Bilimler Üniversitesi, Teknoloji Fakültesi, Elektrik-Elektronik Mühendisliği Bölümü, \\ Isparta, Türkiye \\ ${ }^{3}$ Çevre ve Şehircilik İl Müdürlüğü, Isparta, Türkiye
}

Geliş / Received: 17/10/2019, Kabul / Accepted: 06/04/2020

\section{Öz}

Genellikle soğutucular, PCB/ICs ve elektronik cihazların sıcaklığın belirli bir aralıkta tutmak için yaygın olarak kullanılırlar. Soğutuculardan, hem termal olarak maksimum soğutma hem de çevresindeki komponentlere minimum elektromanyetik girişim (EMI) sağlaması beklenir. Özellikle yüksek frekanslarda çalışan cihazlarda, soğutucuların elektriksel boyutları çalışma frekansının dalga boyuyla karşılaştırılabilir ise bu yapılar anten gibi davranır. Bu çalışmada, elektronik devrelerde kullanılan silindirik yapıdaki soğutucuların EMI davranışları 0-10 GHz frekans bandı için incelenmiştir. Ölçümler tam yansımasız odada gerçekleştirilirken, benzetimler CST MW-Studio benzetim programıyla yapılmış ve elde edilen sonuçlar karşılaştırılmıştır. Benzetim ve ölçüm sonuçlarının birbiri ile uyumlu olduğu görülmüştür. Soğutucunun yansıma katsayısı, ışıma örüntüsü ve E-alan dağılımı elde edilmiştir. Ayrıca tasarım parametrelerine bağlı olarak E-alan değişimleri verilmiştir. Önerilen soğutucunun rezonans frekansı 3,75 GHz olarak elde edilmiş olup ve soğutucunun taban geometrisine bağlıdır. Ayrıca, E-alan dağılım genliğinin frekans artışı ile azaldığı tespit edilmiştir.

Anahtar Kelimeler: Silindirik soğutucu, EMI, elektrik alan, 1şıma örüntüsü, PCB.

\section{Investigation of Electromagnetic Interference from Cylindrical Heatsinks in Electronic Circuits in 0-10 GHz Frequency Band}

\begin{abstract}
The heatsinks are commonly utilized to keep the temperature of PCB/ICs and electronic devices within a certain range. Heatsinks are expected to provide both thermally maximum cooling and minimum electromagnetic interference (EMI) to surrounding components. Especially in devices operating at high frequencies, these structures act as antennas if the electrical dimensions of the heatsinks are comparable to the wavelength of the operating frequency. In this study, the EMI effects of cylindrical heatsinks used in electronic circuits are investigated for the $0-10 \mathrm{GHz}$ frequency band. Simulation and measurement results are in good agreement with each other. The reflection coefficient, radiant pattern and E-field distribution of the heatsink are obtained. In addition to that, E-field changes are given depending on the design parameters. The resonance frequency of the proposed heatsink is obtained as $3.75 \mathrm{GHz}$ and depends on the base geometry of the heatsink. It is also shown that E-field distribution amplitude decrease with frequency increase.
\end{abstract}

Key Words: Cylindrical heatsink, EMI, electric field, radiated pattern, PCB. 


\section{Giriş}

Devrelerdeki sıcaklık artışından kaynaklı arızaları gidermek suretiyle, elektronik cihazların kullanım ömürleri artırılabilir ve bu durum ekonomik açıdan oldukça önemlidir. Elektronik sistemlerin genel arıza nedenlerinin sirasıyla \% 55 sicaklık, \% 20 titreşim, \% 19 nem ve \% 6 toz olduğu tespit edilmiştir (Khattak ve Ali, 2019). Ortamda oluşan sıcaklığın sebep olduğu etkileri en aza indirgemek, araştırmacıları soğutucuların termal açıdan incelenmesine teşvik etmiştir. $\mathrm{Bu}$ istenmeyen sicaklıkların artmasının en önemli nedeni, elektronik devrelerin boyutları küçüldükçe, aynı hacme daha fazla bileşen yerleştirilmesidir. Dolayısıyla, tüketilen güç miktarı artar ve bu artan güç, ortamda daha fazla 1sı oluşmasına sebep olmaktadır. Ayrıca, SMPS, MOSFET, IGBT, BJT ve lineer regülatörler gibi çeşitli devre elemanlarının anahtarlama hızlarının çalışma frekansına bağlı olarak artması da anahtarlama kayıplarından dolayı sıcaklık artışının diğer bir nedenidir.

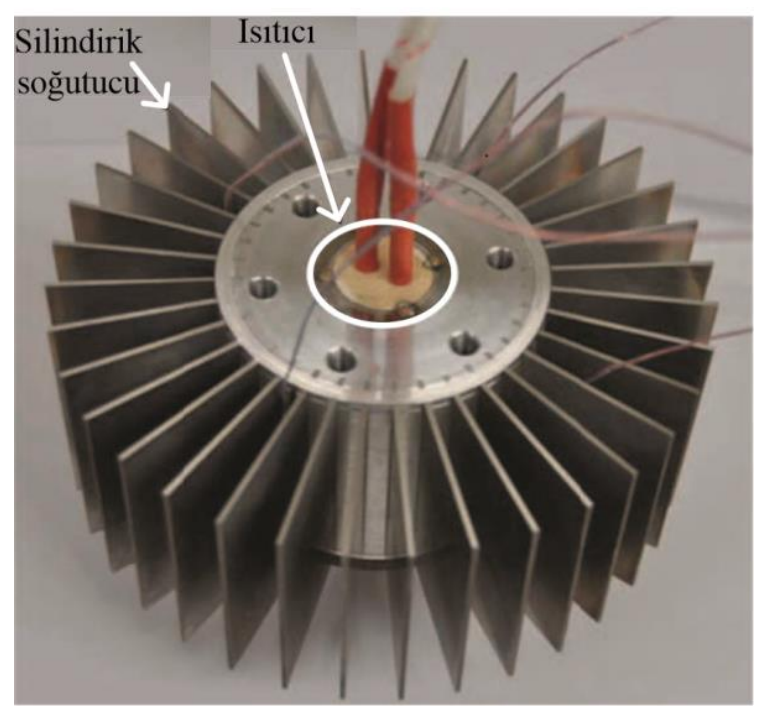

Şekil 1. Bir silindirik soğutucu
Elektronik devrelerdeki 1s1 miktarı, yar1 iletken elemanların çalışma karakteristiğini olumsuz yönde etkileyen önemli bir parametre olduğundan ortaya çıkan 1sı etkin bir şekilde dağıtılmalıdır (Covert vd., 2008; Payendeh vd., 2016). Çeşitli geometrilerdeki metal bloklardan üretilen soğutucular, 1s1 dağıtma işleminde en yaygın kullanılan elemanlardır. İyi iletkenliğe sahip metal malzemelerden yapılmış soğutucuların termal performansı, akışkan miktarı ve yüzey alanlarının arttırılmasıyla iyileştirilebilir. Soğutucular genel olarak aktif ve pasif olarak sinıflandırılmaktadır (Mousavi vd., 2018; Meng, 2018). Pasif soğutucularda kullanılan doğal konveksiyon yönteminde soğutma işlemi, soğutucuya herhangi bir diş destek olmadan termal difüzyonla sağlanmaktadır. $\mathrm{Bu}$ tip soğutucular ilk olarak 1940'larda Elenbaas tarafindan teorik olarak incelenmiştir. Aktif soğutucularda ise, fan gibi elemanlarla soğutucu yüzeyine temas eden hava akışı artırılır (Lampio ve Karvinen, 2018).

Soğutucu yüzey alanının arttırılması termal performansı artırmasına rağmen bazı durumlarda elektromanyetik uyumluluk (EMC) bakımından dezavantajlıdır. Çünkü metal soğutucunun boyutları çalışma frekansı dalga boyuyla karşılaştırılabilir olduğunda, soğutucu anten gibi davranmaktadır. Dolayısıyla soğutucudan yayılan emisyon, PCB üzerine yerleştirilen elektronik devre elemanlarını olumsuz etkilemektedir. Genel olarak soğutucular, hem tabanlarının elektriksel dalga boylarına bağlı olarak yama anten gibi hem de yüksekliklerinin elektriksel dalga boylarına bağlı olarak monopol anten gibi davranmaktadırlar (Park vd., 2009; Manivannan vd., 2010; Genç ve Helhel, 2019). 
Çalışma frekanslarının artmasıyla devredeki anahtarlama hızları artar. Bunun sonucu olarak, anahtarlama elemanlarındaki kayılar, kapasitif veya endüktif kuplajdan dolayı PCB yüzeyiyle soğutucu arasında istenmeyen kaçak akımlara neden olmaktadır. $\mathrm{Bu}$ kaçak akımlar ise soğutucunun istenmeyen 1şımalar yapmasına sebep olarak, soğutuculardan kaynaklı elektromanyetik girişime (EMI) yol açar ve elektronik devre elemanlarının çalışma karakteristiğini değiştirebilir. $\mathrm{Bu}$ nedenle, soğutucuların termal performansının yanı sıra EMI etkisi açısından da performanslarının incelenmesi önemlidir. Literatürde soğutucudan kaynaklı EMI etkilerini azaltmak için filtreleme, ekranlama ve topraklama gibi EMC yöntemleri uygulanmaktadır. Bazı uygulamalarda ise gürültü seviyesini azaltmak için soğurucu malzeme kullanılmaktadır (Diepenbrock vd., 2001; Chiappe, 2011; Doğan vd., 2019).

Soğutucunun geometrisi, 1şıma örüntüsünü belirleyen parametrelerden biridir. Böylece, PCB yüzeyinde soğutucunun daha düşük seviyede emisyon yaydığı yöne diğer komponentler yerleştirilerek EMI etkisi azaltılabilir. $\mathrm{Bu}$ durum yarı iletkenden üretilen bu komponentlerin çalışma performanslarını olumlu yönde etkilemektedir. Dolayısıyla soğutucular, sadece termal açıdan değil aynı zamanda EMI etkisi açısından da IEC CISPR22: 2008 standardına göre elektronik devre tasarımında belirleyici rol oynamaktadır. Tasarım sürecinde EMI problemleri dikkate alınarak hem zaman hem de maliyet açısından avantaj sağlamaktadır (Gong ve Ferreira, 2013).

Silindirik gövdesine eklenen kanatçıklara sahip olan soğutucunun doğal konveksiyon yöntemiyle 1sı transferini analiz eden ve üzerinde kanatçık bulunan yatay silindirik soğutucuların performanslarını inceleyen çeşitli çalışmalar vardır (An vd., 2012; Lee vd., 2016). $\mathrm{Bu}$ soğutucu geometrilerden farklı olarak, dikey kanatçıklara sahip soğutucuların 1s1 transfer hızı, Naftalin Süblimasyon (NS) yöntemiyle belirlenebilir. $\mathrm{Bu}$ yönteme göre, kanatçık ebatları sabit olduğu durumda, 1sı transfer oranının küçük kanatçık aralıkları için sabit olduğu, büyük kanatçık aralıkları için ise 1sı transfer oranının kanatçık yüzey alanıyla arttığ 1 tespit edilmiştir. $\mathrm{Bu}$ yöntemde kullanılan soğutucuların 1s1 transfer katsayısı Zaman Domeninde Sonlu Farklar (FDTD) Yöntemi ve Nusselt sayı korelasyonuyla hesaplanabilir. $\mathrm{Bu}$ hesaplamaya göre, 1s1 transfer katsayısının kanatçığın merkezinden ucuna doğru olan mesafe arttıkça bir asimptotik değere yaklaştı̆̆1 görülmüştür. Soğutucu tipinden farklı olarak, yatay silindirik soğutucularda optimum bir kanatçık aralığı için maksimum ısı transfer hızı elde edilmiştir. Bu tip soğutucularda is1 transfer katsayısının, kanatçık yüksekliğine bağlı olduğu, daha küçük kanatçıklar için daha iyi sonuçlara ulaşıldığı tespit edilmiştir. Günümüzde dikey silindirik soğutucular, Şekil l'de gösterildiği gibi LED aydınlatmaları soğutmak için de yaygın olarak kullanılmaktadırlar.

$\mathrm{Bu}$ çalışmada, elektronik devrelerde kullanılan silindirik yapıdaki soğutucuların EMI davranışları 0-10 frekans GHz bandında incelenmiştir. Ölçümler tam yansımasız odada gerçekleştirilirken, benzetimler CST MW-Studio ${ }^{\circledR}$ programıla yapılmış ve elde edilen sonuçlar karşılaştırılmıştır. Yansıma katsayısı, 1şıma örüntüsü, E-alan dağglımı ve emisyon seviyesi elde edilmiştir. Literatürde silindirik yapıdaki soğutucuların termal analiziyle ilgili çeşitli yayınlar bulunmasına rağmen silindirik soğutucuların anten 
davranışlarıyla ilgili çalışmalar oldukça kısıtlıdır ve bu durum, çalışmamız için temel motivasyon kaynağıdır. Bölüm 2'de, soğutucunun parametrik tasarımı, benzetim ve ölçüm adımları verilmiştir. Bölüm 3'te, elde edilen benzetim ve ölçüm sonuçları değerlendirilmiştir. Ayrıca frekansa bağlı maksimum E-alan değerlerinin değişimim parametrik olarak incelenmiştir.

\section{Materyal ve Metot}

\subsection{Silindirik yapıdaki soğutucunun tasarımı ve ölçümü}

Tasarlanan silindirik yapıdaki soğutucunun perspektif ve üst görünümleri Şekil 2'de gösterilmiştir. Burada tasarım parametreleri soğutucunun çapı $D$, kanatçık yüksekliği $H$, soğutucu uzunluğu $L$, soğutucu taban uzunluğu $L_{b}$, kanatçık kalınlığı $t$, kanatçık sayısı $n$, iki kanatçık arasındaki açı $\alpha$ ve soğuyucuyla toprak düzlem arasındaki aralık $a$ olarak belirtilmiş ve parametrelerin sayısal değerleri Tablo 1'de verilmiştir.

Soğutucunun iç tabanında bulunan silindirik yap1, hem besleme noktası eklemek hem de 1S1 kaynağı yerleştirmek için soğutucu iskeletine eklenmiştir. Kanatçık sayısıyla iki kanatçık arasındaki açı arasındaki ilişki Eşitlik 1'de verilmiştir.

$$
\alpha=\frac{360^{\circ}}{n}
$$

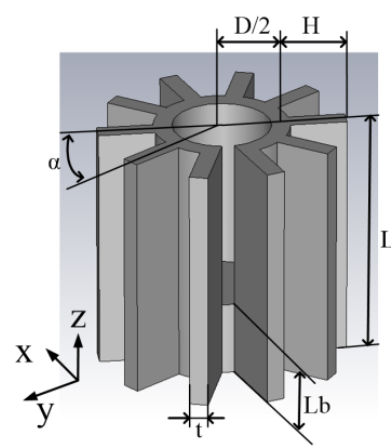

(a)

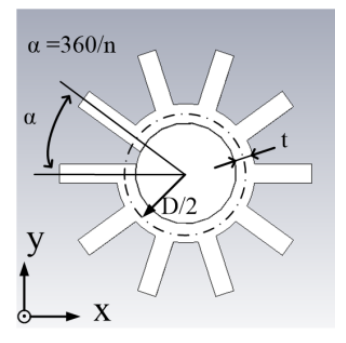

(b)
Şekil 2. Önerilen silindirik soğutucu
Tablo 1. Tasarım parametreleri

\begin{tabular}{cll}
\hline Simge & \multicolumn{1}{c}{ Parametre } & $\begin{array}{c}\text { Uzunluk } \\
(\mathbf{m m})\end{array}$ \\
\hline$D$ & Soğutucunun çapı & 9,5 \\
\hline$H$ & Kanatçık yüksekliği & 5,25 \\
\hline$L$ & Soğutucu uzunluğu & 20 \\
\hline$L_{b}$ & Soğutucu taban uzunluğu & 6 \\
\hline$t$ & Kanatçık kalınlığı & 1,5 \\
\hline$n$ & Kanatçık sayısı & 10 \\
\hline$a$ & Soğuyucuyla toprak & düzlem \\
\hline$\alpha$ & arasındaki aralık & 2 \\
\hline
\end{tabular}

FDTD yöntemiyle çalışan CST MW-Studio programı sayesinde yapılan benzetim ve düzeneği Şekil 3'te verilmiştir. Buna göre, benzetim mesh şekli altıgen ve en uzun mesh uzunluğu $\lambda_{\min } / 20$ 'dir. Sinır koşulları serbest uzay olarak ayarlanmıştır. Benzetim işlemi, $128 \mathrm{~GB}$ SSD ve 16 GB RAM Intel Core i7 2,40 GHz işlemcili bir dizüstü bilgisayarda yapılmıştır. Soğutucunun besleme noktası, toprak düzlem ve soğutucunun merkezine yerleştirilmiştir. Koaksiyel besleme için dielektrik malzeme olarak dielektrik sabiti 2,98 olan $(\tan \delta=0,0023)$ Arlon CLTE (kayıplı) malzemesi kullanılmıştır ve besleme portundan 1 watt'lik EM dalga verilmiştir. Koaksiyel dalga kılavuzunun dış ve iç metal kısımları sırasıyla, toprak zemine ve soğutucuya bağlanmıştır. Dalga kılavuzu empedansını $50 \Omega$ olarak ayarlamak için kılavuzun dış ve iç çapları sırasıyla $8,44 \mathrm{~mm}$ ve $2 \mathrm{~mm}$ olarak belirlenmiştir. Soğutucu tabanı $x$-y ekseninde bulunurken yüksekliği ise $+z$ eksenini boyunca uzanmaktadır. Soğutucu, 6061 alüminyumdan üretilmiştir. Literatürde toprak düzlem çapı minimum $D+6 a$ olarak seçilir. Burada $D$ soğutucunun çap1, $a$ ise soğutucuyla toprak düzlem arasındaki mesafedir (Gonzalez, 1997). Toprak düzlemin taban yarıçapı, soğutucu tabanının yarıçapının iki katıdır ve toprak düzleminin kalınlığı $1 \mathrm{~mm}$ olarak 
ayarlanmıştır. İki katının seçilmesinin sebebi yukarıda belirtilen değerden büyük olmasıdır. Seçilen uzunluktaki toprak düzlem gerçek devrede PCB'yi temsil etmektedir.

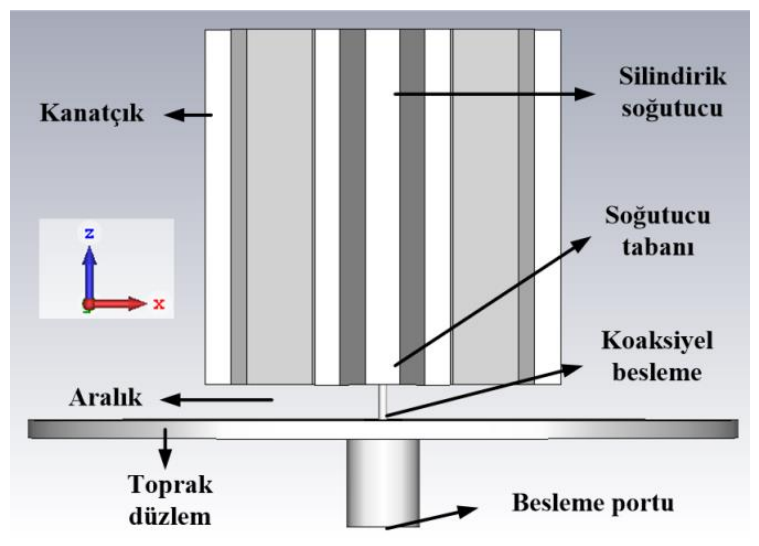

Şekil 3. Benzetim düzeneği

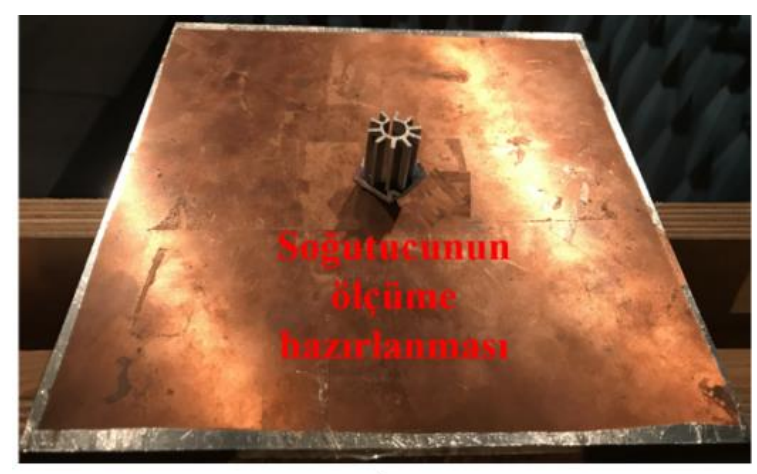

a)

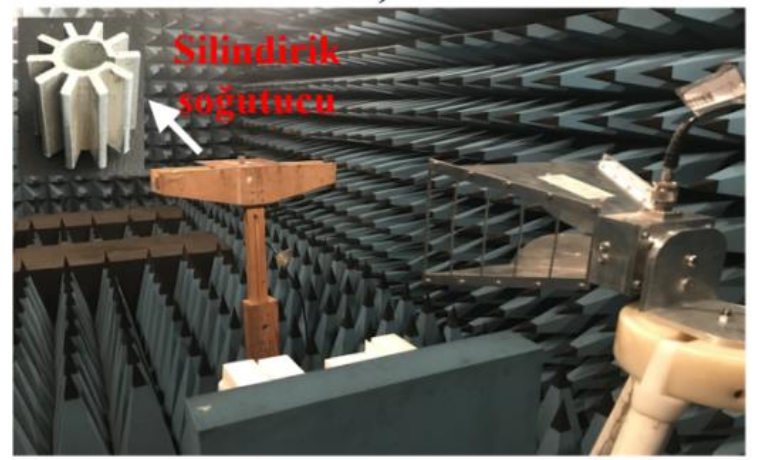

b)

Şekil 4. Ölçüm düzeneği

Çalışmada kullanılan ölçüm düzeneği Şekil 4'te verilmiştir. Rohde \& Schwarz SMF 100A model $(100 \mathrm{kHz}-43,5 \mathrm{GHz})$ sinyal jeneratörüne bağlı $0-18 \quad \mathrm{GHz}$ frekans bandında çalışan double-ridged huni anten, verici anteni olarak kullanılmıştır. Agilent
E4405B model spektrum analizörüne $(9 \mathrm{kHz}$ - 13,2 GHz) bağlı soğutucu ve toprak düzlem alıcı anten olarak çalışır. SMA tipi konektörün canlı ucu soğutucuya diğer ucu ise toprak düzleme bağlanmıştır. Ölçümlerin gerçekleştirildiği yansımasız odanın ebatları $4 \mathrm{~m} \times 4 \mathrm{~m} \times 8 \mathrm{~m}$ 'dir ve vericiyle alıc arasındaki mesafe $1 \mathrm{~m}$ 'dir.

\section{Bulgular}

\section{1. Ölçüm ve benzetim sonuçları}

Soğutucunun benzetim ve ölçüm sonuçlarına göre, 0-10 GHz frekans aralığı için yansıma katsayısı $\left(\left|S_{11}\right|\right)$ ve giriş empedansının reel ve imajiner kısmı Şekil 5'te verilmiştir. Önerilen soğutucunun rezonans frekansı $3,75 \mathrm{GHz}$ olarak elde edilmiş ve yansıma katsayısının genliğinin değeri bu frekansta $-5,1 \mathrm{~dB}$ olarak belirlenmiştir. Daha önce belirtildiği gibi, soğutucular taban geometrilerine bağlı olarak yama anten gibi davranırlar. Bu sonuçlara göre, soğutucu yarı-anten gibi davrandığ gözlenmiştir. Ayrıca, hem benzetim hem de ölçüm aşamalarında giriş empedansı $50 \Omega$ olduğundan dolayı rezonans frekansındaki empedans değeri Şekil 5b'de görüldüğü gibi yaklaşık olarak $50 \Omega$ 'dur. S-parametresi ile giriş empedansı arasındaki ilişki Eşitlik 23 'de verilmiştir. Burada $S_{11}=R+\mathrm{j} X$ olduğu varsayılmıştır (Gonzalez, 1997).

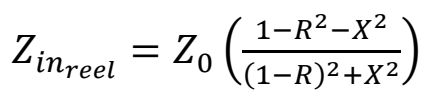

$$
Z_{\text {in } n_{\text {imajiner }}}=Z_{0}\left(\frac{2 j X}{(1-R)^{2}+X^{2}}\right)
$$

Burada, $Z_{\text {in }}$ giriş empedansı ve $Z_{0}$, koaksiyel dalga kılavuzunun karakteristik empedansıdır ve $50 \Omega$ 'a eşittir. 


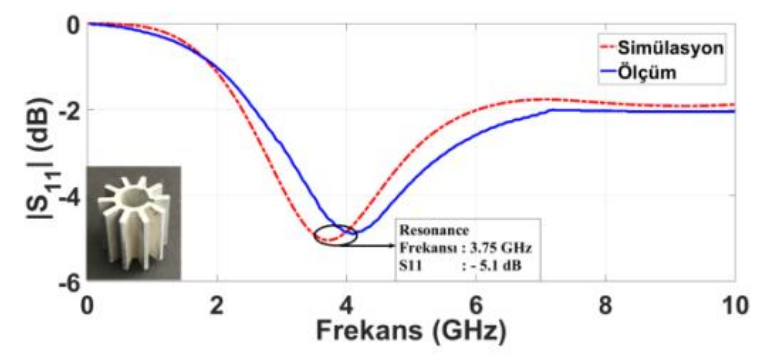

a)

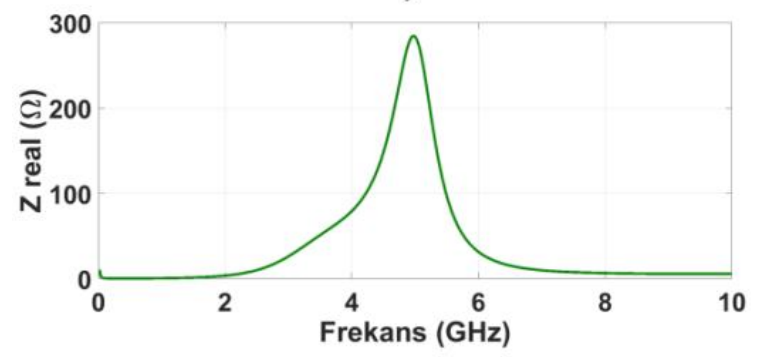

b)

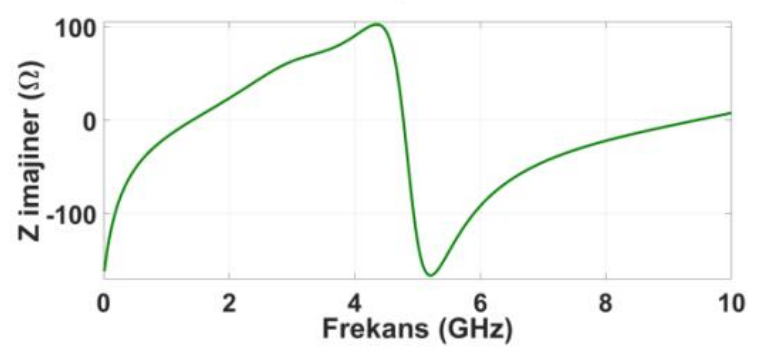

c)

Şekil 5. a) Yansıma katsayısı, giriş empedansının b) reel kısmı, c) imajiner kısmı

Rezonans frekansindaki $\quad(3,75 \quad \mathrm{GHz})$ normalize 1şıma örüntüsü, $x$-y düzlemi $(\theta=$ $\left.90^{\circ}\right)$ ve $x$ - $z$ düzlemi $\left(\theta=90^{\circ}\right.$ ve $\left.\phi=90^{\circ}\right)$ için Şekil 6'da verilmiştir. Rezonans frekansındaki 1şıma değeri, diğer frekans bölgelerindeki 1şıma değerlerinden daha büyük olduğu için $3,75 \mathrm{GHz}$ değeri analiz için tercih edilmiştir. Önerilen soğutucunun 1şıma örüntüsü, yama anteninkine oldukça yakındır. $x-y$ düzlemindeki örüntü, soğutucu geometrisine bağlı olarak beklenildiği gibi simetriktir. Ayrıca, Şekil 6'daki normalize 1şıma örüntüsü incelendiğinde soğutucu tekyönlü (omni-directional) 1şıma karakteristiğine sahip olduğu için kısmen monopole anten gibi 1şıma yapar.
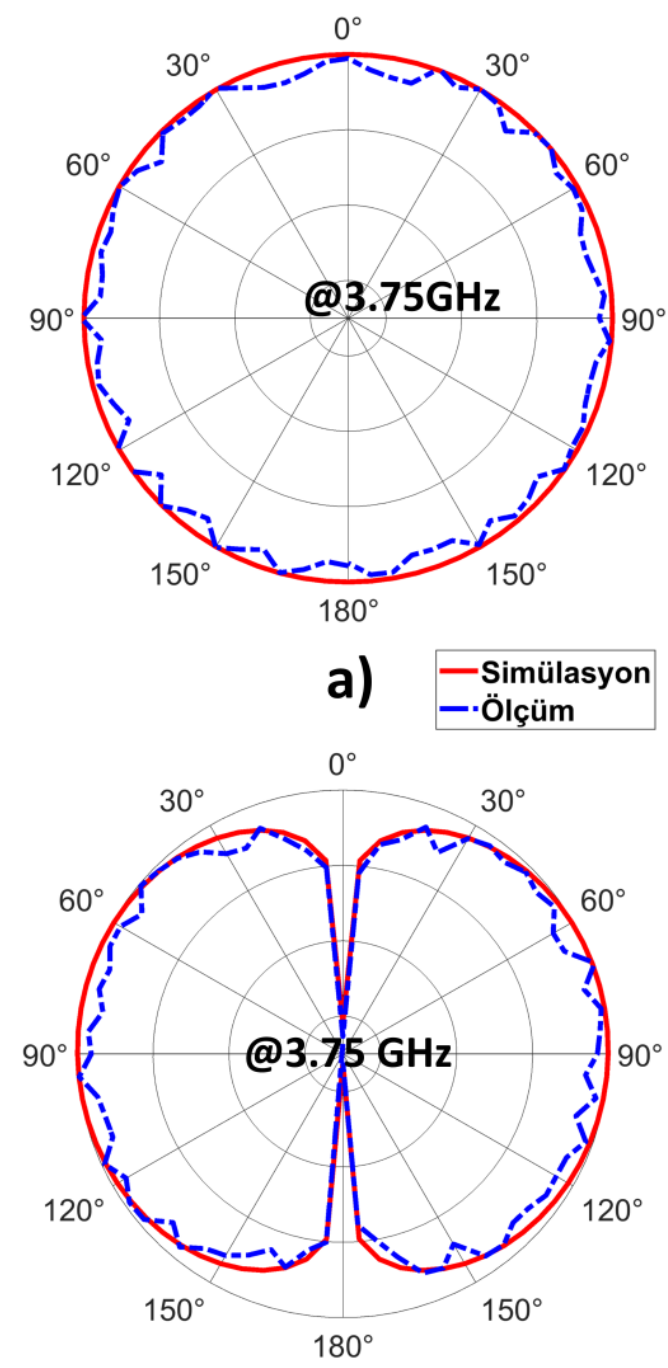

b)

Şekil 6. Rezonans frekansinda $(3,75 \mathrm{GHz})$ normalize 1şıma örüntüsü a) $x-y$ düzlemi, b) $x-z$ düzlemi

Tablo 1'de verilen parametrelerden $L, H$ ve $a$ 'ya göre elde edilen maksimum E-alanının frekansa göre değişimi Şekil 7'de verilmiştir. Bu sonuçlara göre, $L$ değeri arttıkça E-alanın genliği azalmaktadır. Dalga boyuyla frekans ters orantılı olduğu için $L$ uzunluğu arttıkça rezonans frekansının azalması beklenir. $H$ değeri arttıkça, rezonans frekansı artarken Ealan genliği kayda değer bir şekilde değişmemiştir. Diğer yandan, $H$ değerindeki bu artış, soğutucu toplam yüzey alanını arttırdığ etkilemektedir. Son olarak, a uzunluğu 
arttıkça yüksek frekanslarda $(5,5-10 \mathrm{GHz}) \mathrm{E}$ alan değeri azalırken, düşük frekanslarda (0$2,5 \mathrm{GHz})$ ise E-alan değerinin arttı̆̆ görülmektedir. Çünkü çalışma frekansındaki dalga boyu ile $a$ uzunluğu karşılaştırılabilir olduğu durumlarda soğutucunun anten gibi davranmasina neden olur. Bu durum ise EMI açısından risk oluşturmaktadır.

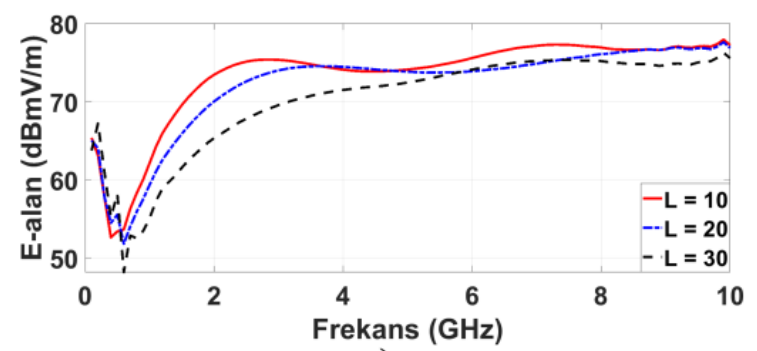

a)

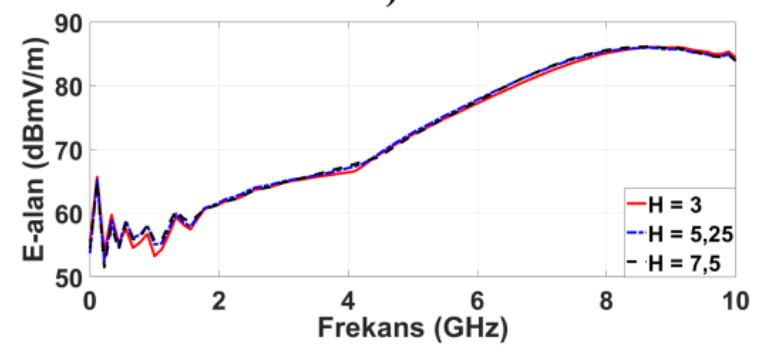

b)

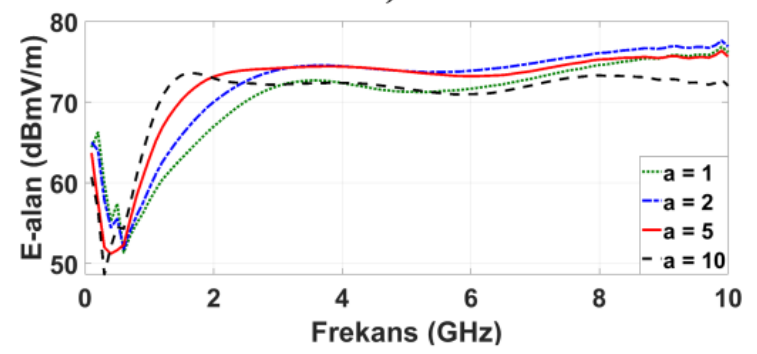

c)

Şekil 7. a) $L$, b) $H$ ve c) $a$ parametrelerine göre elde edilen maksimum E-alanının frekansa göre değişimi

Tablo 1'de verilen parametrelerden $t$ ve $n$ 'ye göre elde edilen maksimum E-alanının frekansa göre değişimi Şekil 8'de verilmiştir.
Buna göre bu tasarım parametrelerin E-alan üzerinde kayda değer bir etkisinin olmadığ tespit edilmiştir. $\alpha$ değeri Eşitlik 1'de verildiği gibi $n$ parametresine bağlı olduğu için grafikte gösterilmemiştir.

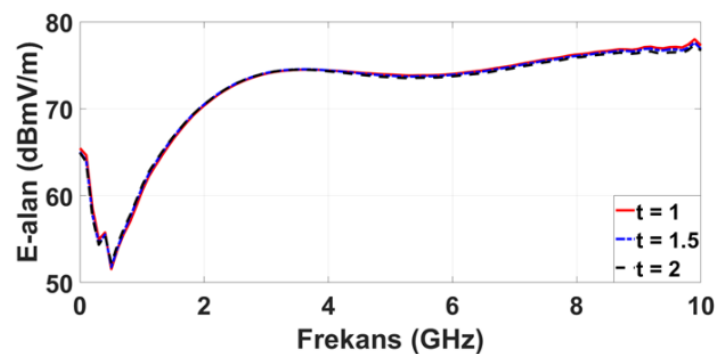

a)

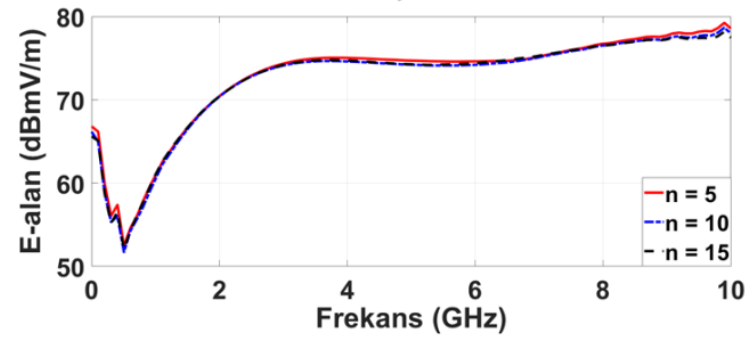

b)

Şekil 8. a) $t$ ve b) $n$ parametrelerine göre elde edilen maksimum E-alanının frekansa göre değişimi

Silindirik soğutucunun sırasıyla 3,75 GHz, 5 $\mathrm{GHz}$ ve $7,5 \mathrm{GHz}$ frekanslarındaki E-alan dağılımları Şekil 9'da verilmiştir. $\mathrm{Bu}$ sonuçlara göre E-alan dağılım şiddetinin, beklenildiği gibi rezonans frekansında daha büyük ve 7,5 GHz'de daha düşük olduğu görülmektedir. Ayrıca silindirik soğutucunun taban ve kanatçıkların uç bölgelerinde oluşan bu dağılım, orta gövde bölgesine göre daha fazla olduğu da tespit edilmiştir. Bunun sebebi sivri uçlarda 1şıma ve saçaklanmanın daha yoğun olmasıdır. E-alan dağılımları tüm frekanslar için düzgün ve simetriktir. 


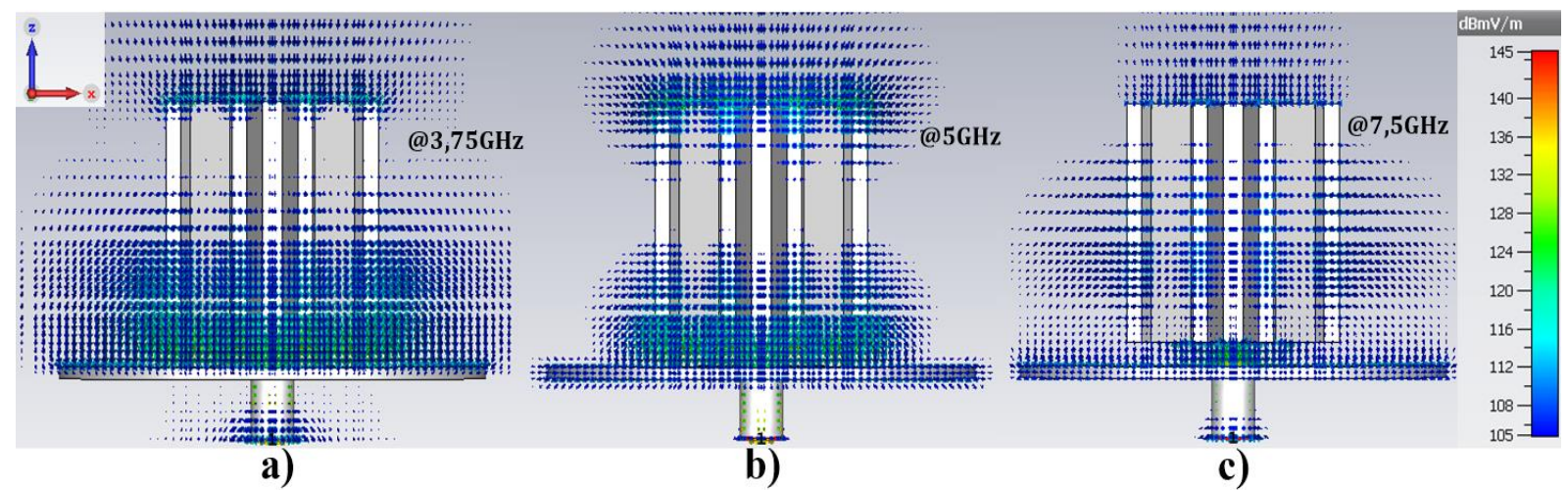

a)

c)

Şekil 9. a) 3,75 GHz, b) $5 \mathrm{GHz}$ ve c) 7,5 GHz frekanslarında soğutucunun E-alan dağılımları

\section{Sonuç ve Tartışma}

Elektronik devrelerde kullanılan silindirik yapıdaki soğutucuların EMI davranışları 0-10 $\mathrm{GHz}$ bandı için bu çalışmada incelenmiştir. Ölçümler tam yansımasız odada gerçekleştirilirken, benzetim CST MWStudio tasarım ortamında yapılmış ve sonuçlar karşılaştırılmıştır.

Benzetim ve ölçüm sonuçlarının birbiri ile uyumlu olduğu görülmüştür. Soğutucunun yansıma katsayısı, 1şıma örüntüsü ve E-alan dağılımı elde edilmiştir. Önerilen soğutucunun rezonans frekansı $3,75 \mathrm{GHz}$ olarak elde edilmiş ve yansıma katsayısının genliğinin değeri bu frekansta $-5,1 \mathrm{~dB}$ olarak belirlenmiştir. Sonuç olarak, soğutucunun taban geometrisine bağlı olarak yama anten gibi davrandığı gözlenmiştir. Rezonans frekansında normalize ışıma örüntüsü $x$-y düzlemi ve $x-z$ düzlemi için belirlendiği durumda, önerilen soğutucunun 1şıma örüntüsü, yama anteninkine oldukça yakındır. $x-y$ düzlemindeki örüntü, soğutucu geometrisine bağlı olarak beklenildiği gibi simetriktir. Ayrıca, E-alan dağılımın genliğinin frekans artışı ile azaldığı ve düzensizleştiği tespit edilmiştir.

\section{Teşekkür}

Ölçümlerin gerçekleştirildiği Akdeniz Üniversitesi Endüstriyel ve Medikal Uygulamalar Mikrodalga Araştırma Uygulama Merkezi (EMUMAM) Müdürlüğüne (Proje No: DPT2007K120530) teşekkürlerimizi sunarız.

\section{Kaynaklar}

An, B. H., Kim, H.J. ve Kim, D.K. 2012. "Nusselt Number Correlation for Natural Convection From Vertical Cylinders with Vertically Oriented Plate Fins", Experimental Thermal and Fluid Science, 41, 59-66.

Chiappe, J. "Additional Techniques to Reduce Heatsink Emissions Utilizing RF Absorbers", In 2012 IEEE International Symposium on Electromagnetic Compatibility, Orlando, 56-63, 2012.

Covert, L., Lin, J., Janning, D. ve Dalrymple, T. 2008. "5.8 GHz Orientation-specific Extruded-fin Heatsink Antennas for 3D RF System Integration", Microwave and Optical Technology Letters, 50(7), 1826-1831.

Diepenbrock, J.C., Archambeault, B. ve Hobgood, L.D. "Improved Grounding Method for Heat Sinks of High Speed Processors", IEEE 51st Electronic 
Components and Technology Conference, Orlando, USA, 993-996, 2001.

Dogan, H., Basyigit, I.B. ve Genc, A. "Variation of Radiated Emission from Heatsinks on PCB according to Fin Types", IEEE 3rd International Symposium on Multidisciplinary Studies and Innovative Technologies, Ankara, 11-13 October 2019.

Genc, A. ve Helhel, S. "The Comparison of EM Characteristics of the Heatsinks with Equal Base Area depending on the Various Geometries", 10th International Symposium on Intelligent Manufacturing and Service Systems, Sakarya Üniversitesi, Sakarya, 979985. 2019.

Gong, X. ve Ferreira, J.A. 2013. "Investigation of Conducted EMI in SiC JFET Inverters using Separated Heat Sinks", IEEE Transactions on Industrial Electronics, 61(1), 115-125.

Gonzalez, G. (1997). "Microwave Transistor Amplifiers: Analysis and Design 2nd ed.", Prentice Hall, New York, 4-31.

Khattak, Z. ve Ali, H. M. 2019. "Air Cooled Heat Sink Geometries subjected to Forced flow: A Critical Review", International Journal of Heat and Mass Transfer, 130, 141-161.

Lampio, K. ve Karvinen, R. 2018. "A New Method to Optimize Natural Convection Heat Sinks", Heat and Mass Transfer, 54(8), 2571-2580.

Lee, J., Kim, H. ve Kim, D.K. 2016. "Experimental Study of Natural Convection Cooling of Vertical Cylinders with Inclined Plate Fins", Energies, 9(391), 1-15.
Manivannan, S., Arumugam, R., Paramasivam, S., Salil, P. ve Rao, B.S. 2010. "HFSS Simulation, Experimental Investigation and Optimisation of Heat Sink EMI", IET Power Electronics, 3(6), 881-891.

Meng, X., Zhu, J., Wei, X. ve Yan, Y. 2018. "Natural Convection Heat Transfer of a Straight-fin Heat Sink", International Journal of Heat and Mass Transfer, 123, 561-568.

Mousavi, H., Darzi, A.A.R., Farhadi, M. ve Omidi, M. 2018. "A Novel Heat Sink Design with Interrupted, Staggered and Capped Fins", International Journal of Thermal Sciences, 127, 312-320.

Park, H.H., Jung, J.H., Jang, T.S., Han, S.T., Song, S.H., Park, J.J., ve Park, H.B. 2009. "Prediction of Radiated EMI from PCB Excited by Switching Noise of IC", Microwave and Optical Technology Letters, 51(10), 2262-2266.

Payandeh, M., Belov, I., Jarfors, A.E. ve Wessén, M. 2016. "Effect of Material Inhomogeneity on Thermal Performance of a Rheocast Aluminum Heatsink for Electronics Cooling", Journal of Materials Engineering and Performance, 25(6), 2116-2127. 